Article

\title{
In Vitro Propagation of Rheophytic Orchid, Epipactis flava Seidenf.-A Comparison of Semi-Solid, Continuous Immersion and Temporary Immersion Systems
}

\author{
Boworn Kunakhonnuruk, Phithak Inthima and Anupan Kongbangkerd * \\ Plant Tissue Culture Research Unit, Department of Biology, Faculty of Science, Naresuan University, Phitsanulok \\ 65000, Thailand; bowornk57@email.nu.ac.th (B.K.); Phithaki@nu.ac.th (P.I.) \\ * Correspondence: Anupank@nu.ac.th
}

Received: 14 August 2019; Accepted: 20 September 2019; Published: 24 September 2019

check for updates

\begin{abstract}
Epipactis flava Seidenf. is an endangered Thai rheophytic orchid that has recently shown a rapid decrease in its natural habitat, prompting an urgent need for conservation using ex situ reintroduction methods. Temporary immersion system (TIS) has been successfully applied for large-scale propagation in various plants species. Propagation efficiency of E. flava using TIS was investigated and compared with conventional semi-solid system (SSS) and liquid continuous immersion system (CIS). The highest percentage of new shoot and shoot bud formation was obtained from TIS, followed by CIS and SSS, respectively. Growth parameters as indicated by number of new shoots, shoot buds, shoot height and leaves per explant were significantly higher using TIS than with SSS and CIS. Moreover, the maximum number of new shoots and shoot buds per replication were reliably obtained from TIS higher than SSS and CIS. After acclimatization, the highest survival percentage of plantlets was observed in TIS (76.7\%), with $60 \%$ surviving after eight weeks of transplantation in artificial stream. TIS was determined as the most suitable culture system for in vitro mass propagation of E. flava compared to CIS and SSS.
\end{abstract}

Keywords: liquid medium; Epipactis flava; rheophytic orchid; conservation

\section{Introduction}

A rheophytic lifestyle appears to be very rare in Orchidaceae, and the only rheophytic orchid found in Thailand is Epipactis flava [1]. Intricate morphological details and life cycle of E. flava were described by Pedersen et al. [2] and Kunakhonnuruk et al. [3], respectively. In Thailand, E. flava grows in streams with calcareous substrates [2]. Presently, only 10 natural sites of E. flava have been found in Nan, Kanchanaburi and Tak Provinces [1] and its current conservation status is classified as an endangered species [4,5]. Loss of natural habitat due to erosion and human activity have accelerated the rate of population decline. Urgent action is now required for E. flava conservation. Plant tissue culture is recognized as a high-performance tool for ex situ conservation of endemic and endangered orchid species [6-8]. Recently, successful in vitro seed germination and seedling culture of E. flava was reported [3]. However, for in vitro mass propagation, conventional techniques using semi-solid or shake-flask cultures are labor intensive during the subculturing period. To overcome these problems, bioreactor systems have been developed and improved. Recently, several novel bioreactor systems have shown promise, including temporary immersion system (TIS), which are recognized as a key process for mass propagation and commercial exploitation of plant tissue cultures [9]. Moreover, TIS and other novel plant bioreactors based on micropropagation have been used to increase plant culture multiplication rates and successfully applied commercially [10-12] for mass production of medicinal 
plants [13,14] and for conservation of endangered species [8]. During in vitro culture conditions, plants are grown under the high relative humidity, low light intensity, constant temperature-in contrast to ex vitro environment. Hence, intensive acclimatization and transplantation of plantlets or seedlings from the in vitro to ex vitro environment was necessary. This new research technology offers the possibility of large-scale E. flava cultivation. Greenhouse acclimatization of in vitro derived plantlets was investigated as well to establish a complete propagation program applicable for species reintroduction or ex situ conservation.

\section{Materials and Methods}

\subsection{Evaluation of Different In Vitro Culture Systems}

The germination of $E$. flava seeds obtained from green pod was performed under aseptic condition in $120 \mathrm{~mL}$ culture vessel containing $20 \mathrm{~mL}$ of semi-solid medium. After few months, in vitro seedlings of E. flava with two to three leaves were cultured on modified Murashige and Skoog medium [15] supplemented with $150 \mathrm{~mL} \mathrm{~L}^{-1}$ coconut water (CW), $50 \mathrm{~g} \mathrm{~L}^{-1}$ potato extract (PE) and $20 \mathrm{~g} \mathrm{~L}^{-1}$ sucrose [3] for two months before being used as explants. Explants of E. flava with two to three buds differentiated from rhizomes that were cultured in semi-solid system (SSS), continuous immersion system (CIS) and TIS using the same medium. The SSS system was performed with a $120 \mathrm{~mL}$ of bottle holding $20 \mathrm{~mL}$ of medium solidified with $7.5 \mathrm{~g} \mathrm{~L}^{-1}$ agar and $2 \mathrm{~g} \mathrm{~L}^{-1}$ activated charcoal, whereas CIS was conducted with a $125 \mathrm{~mL}$ conical flask containing $20 \mathrm{~mL}$ liquid medium and shaken on a $110 \mathrm{rpm}$ rotary shaker. One explant per vessel was performed for SSS and CIS. Each culture system consists of three replications and each replication contain 20 vessels. A TIS system modified from Escalona et al. [16] was set up as well using $1 \mathrm{~L}$ of twin-bottle supported with glass beads for the cultivating bottle. Twenty explants were cultured in a TIS vessel containing $400 \mathrm{~mL}$ liquid medium. One TIS set represented one replicate, and three replicates were set up for this system. The liquid medium in TIS was fed for $5 \mathrm{~min}$ every $4 \mathrm{~h}$. All culture systems were maintained under 12/12 h light/dark photoperiods with $40 \mu \mathrm{mol} \mathrm{m}^{-2} \mathrm{~s}^{-1}$ light intensity using a warm-white LED lamp (BIOLED-SET-18W, BioBULB ${ }^{\circledR}$, United Digital Corporation CO., LTD., Bangkok, Thailand) for four weeks. Survival rate, plant quality and quantity were observed to evaluate propagation efficiency of the different culture systems.

\subsection{Greenhouse Acclimatization and Ex Vitro Culture}

Plantlets of E. flava from the different culture systems were used for acclimatization and ex vitro cultivation. In vitro plantlets were rinsed with running tap water to eliminate the culture medium. Subsequently, they were individually transplanted into plastic slit pots $(4 \mathrm{~cm}$ diameter, $4 \mathrm{~cm}$ depth) containing mixed potting medium; Hydroton (4 mm diameter; POPPER, Wiwan Technology, Chiang Mai, Thailand): Pumice (5 mm diameter; Lombok Pumice Stone, Semarang, Indonesia) (1:1). After that, plantlets containing in plastic slit pots were placed in a transparent plastic box $(36 \times 50 \times 14 \mathrm{~cm})$ for nine weeks of acclimatization. The plantlets were watered once a week and sprayed with liquid N-P-K fertilizer (1 $\left.\mathrm{g} \mathrm{L}^{-1}\right)$ (20-20-20; WESCO chemicals Thailand CO., LTD., Bangkok, Thailand) every two weeks. After nine weeks of acclimatization, the plantlets were transferred for cultivation in an artificial stream for a further eight weeks under a greenhouse environment (ambient temperature 27 to $32{ }^{\circ} \mathrm{C}$, relative humidity $50 \%$ to $60 \%$ and natural sunlight with an average of $250 \mu \mathrm{mol} \mathrm{m}{ }^{-2} \mathrm{~s}^{-1}$ light intensity under $70 \%$ shade nets). Survival rate and plant quality were evaluated and recorded.

\subsection{Statistical Analysis}

Complete randomized design was employed. Differences of each parameter among the various culture systems were statistically compared by one-way ANOVA followed by Duncan's new Multiple Range Test (DMRT) using SPSS program ver. 17.0 (SPSS ${ }^{\circledR}$, New York, NY, USA). 


\section{Results}

\subsection{Growth and Development of E. flava Plantlets Under Different In Vitro Culture Systems}

Propagation efficiencies of E. flava in SSS, CIS and TIS were evaluated and compared. One hundred percent survival rates of plantlets were found in all culture systems. Explants from the tested culture systems grew well and some proliferated new shoots and shoot buds (Figure 1). No hyper hydric symptoms were observed in the explants after four weeks of culture. Regeneration and proliferation efficiency of explants grown in the three culture systems showed obvious differences. Quality of regenerated plantlets was classified into three levels, as illustrated in Figure 2a. Results revealed the highest percentage of healthy growing plantlets in TIS (53.3\%) followed by SSS (20.0\%) and CIS (5.5\%), respectively (Figure $2 \mathrm{~b}$ ). More than $50 \%$ of poor-quality plantlets were observed in both SSS and CIS. TIS showed higher positive influence on growth and development of E. flava than SSS and CIS (Table 1). The highest percentages of new shoot formation (96.7\%) and shoot bud formation (91.7\%) were observed in TIS followed by SSS (46.7\%) and CIS (40.0\%), respectively. In addition, TIS promoted the growth of new shoots ( 1.5 shoots per explant), shoot buds ( 8.1 shoot buds per explant) and roots (4.4 roots per explant) and stimulated shoot height (29.4 mm per shoot) and number of leaves (4.4 leaves per shoot) more than SSS and CIS as well. Orchid shoot heights in TIS were up to two-folds higher than in SSS and CIS. A comparison of total number of new shoots and shoot buds obtained from one replication (20 explants per replication) revealed that the TIS system resulted in significantly higher amounts of both new shoots (29.3) and shoot buds (161.0) than SSS and CIS systems (Table 1).

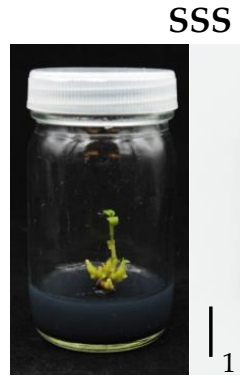

SSS

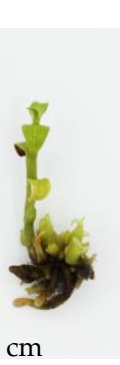

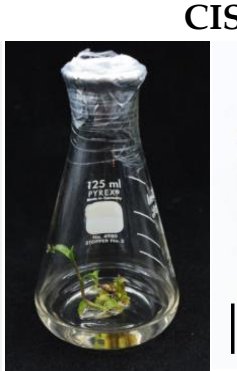

CIS

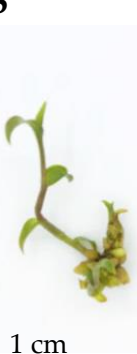

TIS

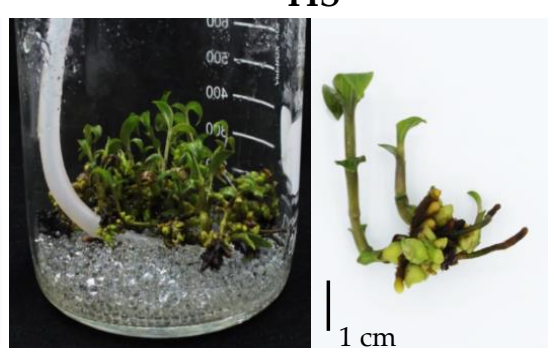

Figure 1. Growth and development of Epipactis flava plantlets at four weeks after culture in semi-solid system (SSS), continuous immersion system (CIS) and temporary immersion system (TIS).

Table 1. Effect of culture systems on growth and development of Epipactis flava plantlets for four weeks of culture.

\begin{tabular}{cccc}
\hline Parameter & \multicolumn{3}{c}{ Culture Systems ${ }^{1}$} \\
\cline { 2 - 4 } & SSS & CIS & TIS \\
\hline Survival rate (\%) & $100.0 \pm 0.0 \mathrm{~ns}$ & $100.0 \pm 0.0$ & $100.0 \pm 0.0$ \\
New shoot formation (\%) & $86.7 \pm 0.6 \mathrm{~b}$ & $70.0 \pm 1.1 \mathrm{c}$ & $96.7 \pm 1.3 \mathrm{a}$ \\
Number of new shoots per explant & $1.0 \pm 0.0 \mathrm{~b}$ & $0.8 \pm 0.2 \mathrm{~b}$ & $1.5 \pm 0.1 \mathrm{a}$ \\
Number of new shoots per replication & $19.0 \pm 1.0 \mathrm{~b}$ & $15.7 \pm 1.5 \mathrm{~b}$ & $29.3 \pm 8.6 \mathrm{a}$ \\
Shoot bud formation (\%) & $46.7 \pm 1.3 \mathrm{~b}$ & $40.0 \pm 1.1 \mathrm{~b}$ & $91.7 \pm 1.7 \mathrm{a}$ \\
Number of shoot buds per explant & $3.9 \pm 0.1 \mathrm{~b}$ & $5.5 \pm 0.2 \mathrm{~b}$ & $8.1 \pm 0.4 \mathrm{a}$ \\
Number of shoot buds per replication & $78.7 \pm 5.5 \mathrm{~b}$ & $110.7 \pm 14.6 \mathrm{~b}$ & $161.0 \pm 35.6 \mathrm{a}$ \\
Number of roots per explant & $3.8 \pm 0.0 \mathrm{ab}$ & $3.6 \pm 0.0 \mathrm{~b}$ & $4.4 \pm 0.1 \mathrm{a}$ \\
Number of leaves per shoot ${ }^{2}$ & $2.8 \pm 0.1 \mathrm{~b}$ & $2.7 \pm 0.5 \mathrm{~b}$ & $4.4 \pm 0.1 \mathrm{a}$ \\
Shoot height (mm) ${ }^{2}$ & $14.0 \pm 0.4 \mathrm{~b}$ & $14.3 \pm 3.4 \mathrm{~b}$ & $29.4 \pm 0.8 \mathrm{a}$ \\
\hline
\end{tabular}

Values are mean \pm SE of three replications (20 explants per replication) except number of new shoot and shoot bud per replication are mean $\pm \mathrm{SD}$ of three replications. The same letter within a row was not significantly different at $p$ $\leq 0.05$ according to DMRT. ${ }^{1}$ SSS - Semi-solid system; CIS - Continuous immersion system and TIS-Temporary immersion system. ${ }^{2}$ Number of leaves per shoot and shoot height were recorded from the longest shoot of each explant. 
a Grade of growth and development
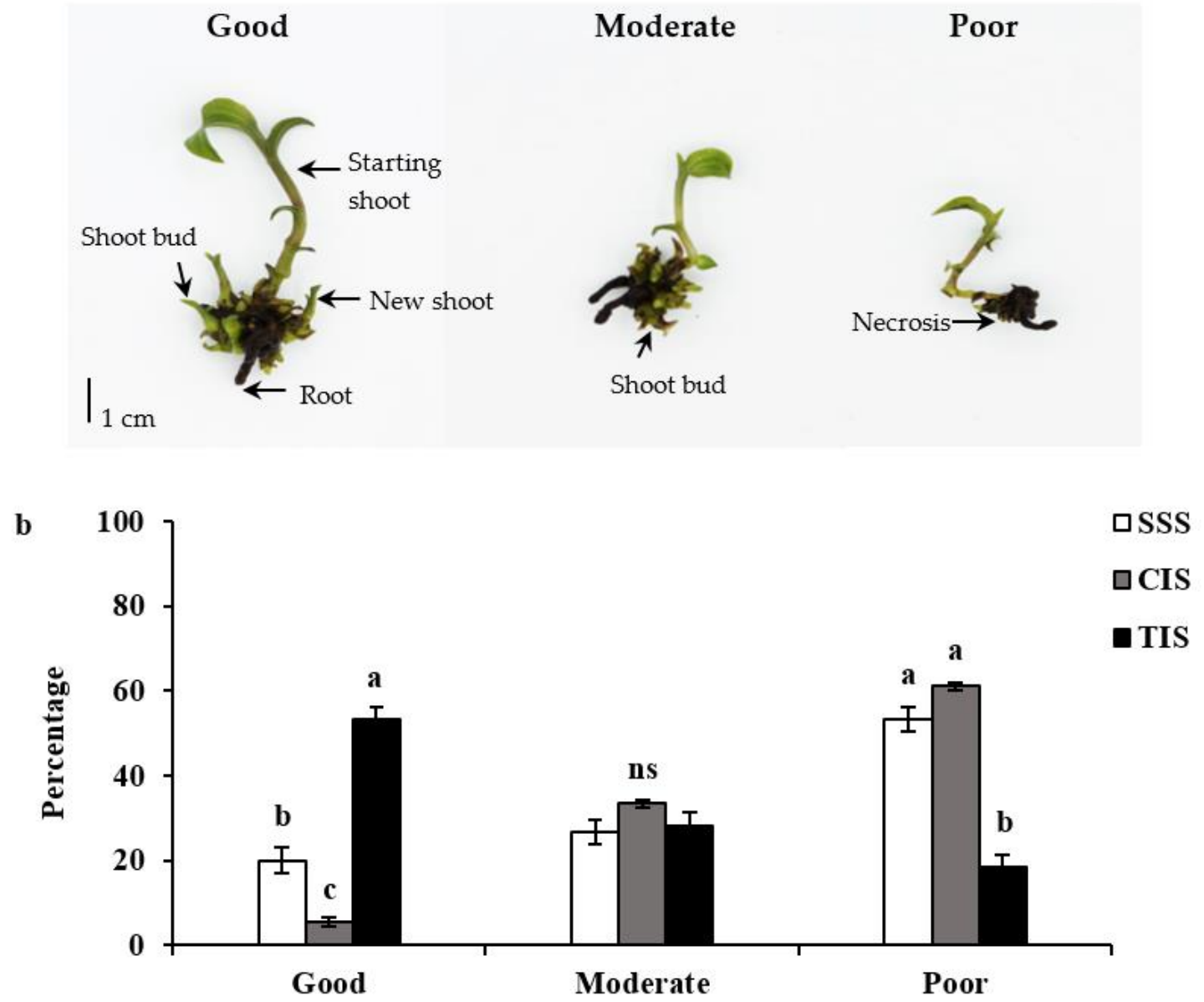

\section{Grade of growth and development}

Figure 2. Classifying system for growth of Epipactis flava plantlets (a) and comparative effects of culture systems on growth of Epipactis flava plantlets after four weeks of culture (b). Results represent the mean \pm SE of three replications from 20 explants. Different letters within the same grade of growth were significantly different at $p \leq 0.05$ according to Duncan's Multiple Range Test (DMRT).

\subsection{Acclimatization and Ex Vitro Culture of Plantlets Derived From Different In Vitro Culture Systems}

Survival and growth of E. flava plantlets obtained from different in vitro culture systems were investigated under acclimatization condition. Complete hardening was established at nine weeks. Different plant qualities of $E$. flava were evaluated according to the following criteria: dead plant; poor growth plant, survived plant with no new shoots or shoot bud formation; good growth plant and survived plant with new shoots or shoot bud formation (Figure 3a). The highest survival rate was observed in plantlets obtained from TIS (76.7\%) whereas less than $50 \%$ of plantlets derived from SSS and CIS survived after acclimatization (Figure 3a). In addition, most plants showing good growth (38.9\%) were found in TIS-derived plantlets followed by plantlets from SSS $(28.9 \%)$ and CIS $(23.3 \%)$, respectively. The last cultivation step of E. flava plantlets was performed after acclimatization with transfer to an artificial stream under a greenhouse environment for eight weeks. Results revealed that E. flava plantlets obtained from TIS had approximately two-fold higher survival rates $(60 \%)$ during cultivation in an artificial stream than plantlets from SSS and CIS (Figure 3b). 


\section{Acclimatization}

a

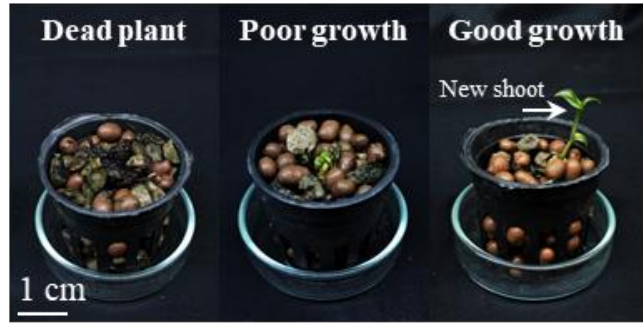

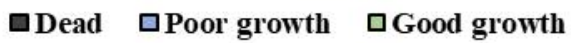

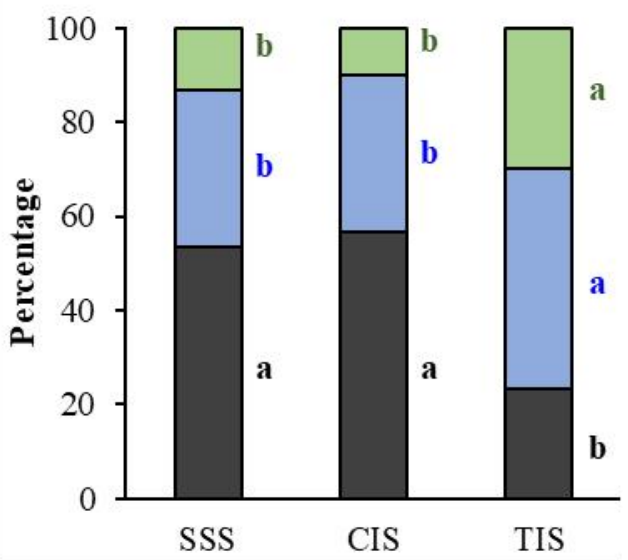

Transplantation

b

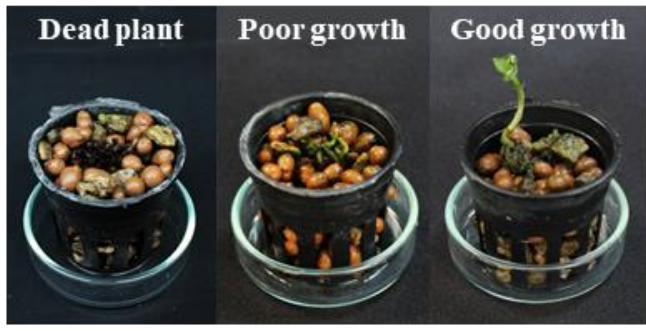

口Dead $\square$ Poor growth $\square$ Good growth

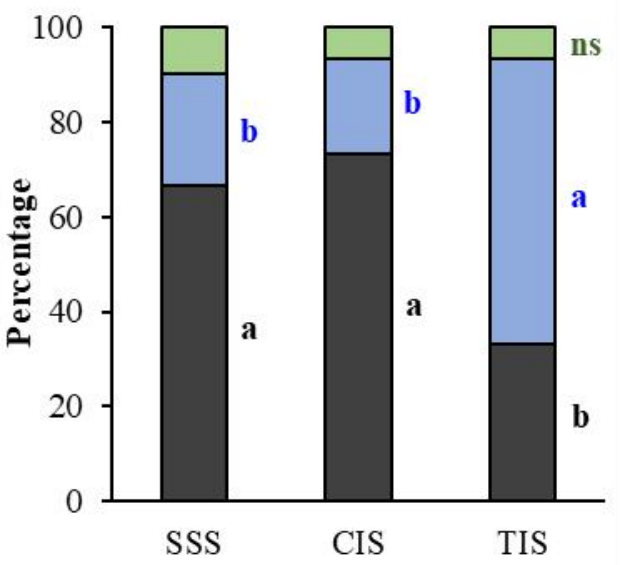

Figure 3. Plant quality and growth of Epipactis flava after acclimatization for nine weeks (a) and after transplantation within an artificial stream for eight weeks (b). Results are the mean of three replications (20 plants per replication). The same letter of each observation parameter was not significantly different at $p \leq 0.05$ according to DMRT.

\section{Discussion}

Advances in in vitro culture techniques such as TIS have recently been developed to improve mass propagation efficiency that was difficult to accomplish using conventional propagation systems such as SSS or CIS [17]. TIS mass propagation success has previously been reported for various plant species $[18,19]$ —including orchids $[11,20,21]$. Prior reports revealed that different culture systems resulted in diverse growth and morphogenesis of cultured plants [11,14,22]. The highest ratio of normal plantlets was obtained in TIS treatment, whereas SSS and CIS methods exhibited higher plant-abnormality rate $[18,23]$. The SSS medium possibly provided less nutrient absorption than TIS and CIS [16], while CIS frequently induced abnormality and necrosis symptoms resulting from permanent immersion [24]. Better growth and proliferation of E. flava plants cultured by CIS over SSS were reported by Kunakhonnuruk et al. [3]; however, no differences were observed under shorter culturing time. Therefore, large-scale mass production of E. flava by CIS was not recommended, although this plant generally displays a rheophytic habit. Results indicated that TIS was a more suitable method for large-scale mass production of this endangered orchid, with better growth and proliferation of E. flava than SSS and CIS. Undesirable symptoms as explained by browning appearance at the root were found in E. flava cultured under TIS lower than SSS and CIS. Furthermore, TIS showed better shoot and shoot bud proliferation as well as root and leaf induction numbers compared to SSS and CIS. Relatively similar results were found in Vanilla planifolia [25] and Rubus spp. as well [26]. One advantage of TIS over SSS and CIS is the alteration between aeration and periodical immersion of explants in a liquid medium which improves gaseous exchange, increases oxygen supply and reduces hyperhydration [27-29]. Furthermore, TIS eliminates some toxic gases as well, i.e., ethylene, during air feeding immersion cycles [30], whereas air ventilation is not an option in closed systems such as 
SSS and CIS. Photomixotrophic culture was enhanced during renewal of atmosphere in TIS which stimulated better growth and development of E. flava than SSS and CIS.

Acclimatization is an important procedure to support successful plantlet transplantation from the in vitro to ex vitro environment [31,32]. This process allows in vitro plantlets to survive and adapt to the natural environment which normally has higher light intensity and lower humidity than in vitro conditions [31]. During the acclimatization process, plantlets of E. flava obtained from TIS gave higher survival rates and successfully grew and adapted under environmental change. By contrast, morphological plantlet disorders were mostly derived from SSS and CIS. Many previous reports indicated that plantlets from TIS had greater growth, with rapid adaptation after exposure to ex vitro conditions than SSS and CIS derived plant $[18,33]$. This might be because TIS enhanced stomatal functioning and improved photosynthesis and transpiration [31,34]. However, E. flava plantlets visibly wilted during transfer to ex vitro acclimatization. Related reports found that wilting symptoms caused by temporary dormancy during transplantation could occur in some species, i.e., Eulophia cullenii [35] and Calopogon tuberosus [36]. Plantlets of E. flava from all culture systems were transferred at the acclimatization step to cultivation in artificial streams for a further eight weeks. Results revealed that TIS derived plantlets had higher survival percentage than those from SSS and CIS. Therefore, to promote the reintroduction program of this endangered orchid, TIS offers a suitable in vitro culture system for the continuous mass production of healthy plantlets within a short time and rapidly encourages acclimatized plantlets to natural environments.

\section{Conclusions}

This is the first study comparing TIS for mass propagation of E. flava against CIS and SSS. TIS was found to be the most efficient and suitable method for mass propagation of E. flava. Plantlets obtained from TIS successfully adapted and had the highest survival rate during acclimatization and ex vitro culture. TIS significantly improved mass propagation and offers advantages for ex situ conservation of E. flava.

Author Contributions: B.K. completed the experiments and draft manuscript. P.I. responsible for research suggestion, result interpretation and editing draft manuscript. A.K. designed experiments, supporting facilities and finalized the manuscript. All authors have read and approved the manuscript.

Funding: Naresuan University, Phitsanulok, Thailand.

Acknowledgments: This study was facilitated by the Plant Tissue Culture Research Unit, Department of Biology, Faculty of Science, Naresuan University, Thailand. The first author would like to thank the Science Achievement Scholarship of Thailand (SAST) for providing a scholarship to conduct this research.

Conflicts of Interest: The authors declare that they have no conflicts of interest.

\section{References}

1. Pedersen, H.; Srimuang, K.; Banziger, H.; Watthana, S. Pollination-system diversity in Epipactis (Orchidaceae): New insights from studies of E. flava in Thailand. Plant Syst. Evol. 2018. [CrossRef]

2. Pedersen, H.; Watthana, S.; Srimuang, K. Orchids in the torrent: On the circumscription, conservation and rheophytic habit of Epipactis flava. Bot. J. Linn. Soc. 2013, 172, 358-370. [CrossRef]

3. Kunakhonnuruk, B.; Inthima, P.; Kongbangkerd, A. In vitro propagation of Epipactis flava Seidenf., an endangered rheophytic orchid: A first study on factors affecting asymbiotic seed germination, seedling development and greenhouse acclimatization. Plant Cell Tiss. Organ Cult. 2018, 135, 419-432. [CrossRef]

4. Santisuk, T.; Chayamarit, K.; Pooma, R.; Suddee, S. Thailand Red Data: Plants; Integrated Promotion Technology: Bangkok, Thailand, 2006.

5. Chamchumroon, V.; Nanthawan, S.; Naiyana, T.; Manop, P.; Sommanussa, T. Threatened Plants in Thailand; Department of National Parks, Wildlife and Plant Conservation: Bangkok, Thailand, 2017; p. 224. 
6. Aggarwal, S.; Zettler, L.W. Reintroduction of an endangered terrestrial orchid, Dactylorhiza hatagirea (D. Don) Soo, assisted by symbiotic seed germination: First report from the Indian subcontinent. Nat. Sci. 2010, 8, 139-145.

7. Wu, R.Z.; Baque, M.A.; Paek, K.Y. Establishment of a large-scale micropropagation system for Anoectochilus formosanus in bioreactors. Acta Hortic. 2014, 878, 167-174. [CrossRef]

8. Zhang, B.; Sarsaiya, S.; Pan, X.; Jin, L.; Xu, D.; Zhang, B. Optimization of nutritional conditions using a temporary immersion bioreactor system for the growth of Bletilla striata pseudobulbs and accumulation of polysaccharides. Sci. Hortic. 2019, 240, 155-161. [CrossRef]

9. Sharma, M.; Gupta, R.; Khajuria, R.K.; Mallubhotla, S.; Ahuja, A. Bacoside biosynthesis during in vitro shoot multiplication in Bacopa monnieri (L.) Wettst. grown in Growtek and air lift bioreactor. Indian J. Biotechnol. 2015, 14, 547-551.

10. Snyman, S.J.; Nkwanyana, P.D.; Watt, M.P. Alleviation of hyperhydricity of sugarcane plantlets produced in RITA $^{\circledR}$ vessels and genotypic and phenotypic characterization of acclimated plants. S. Afr. J. Bot. 2011, 77, 685-692. [CrossRef]

11. Moreira, A.L.; Silva, A.B.; Santos, A.; Reis, C.O.D.; Landyraf, P.R.C. Cattleya walkeriana growth in different micropropagation systems. Ciênc. Rural 2013, 43, 1804-1810. [CrossRef]

12. Frometa, O.M.; Morgado, M.M.E.; Silva, J.A.T.; Morgado, D.T.P.; Gradaille, M.A.D. In vitro propagation of Gerbera jamesonii Bolus ex Hooker f. in a temporary immersion bioreactor. Plant Cell Tiss. Organ Cult. 2017, 129, 543-551. [CrossRef]

13. Ibrahim, R. The potential of bioreactor technology for large-scale plant micropropagation. Acta Hortic. 2017, 1155, 573-584. [CrossRef]

14. Vives, K.; Andujar, I.; Lorenzo, J.C.; Concepcion, O.; Hernandez, M.; Escalona, M. Comparison of different in vitro micropropagation methods of Stevia rebaudiana B. including temporary immersion bioreactor (BIT ${ }^{\circledR}$ ). Plant Cell Tiss. Organ Cult 2017. [CrossRef]

15. Murashige, T.; Skoog, F. A revised medium for rapid growth and bioassays with tobacco tissue cultures. Physiol. Plant 1962, 15, 473-497. [CrossRef]

16. Escalona, M.; Lorenzo, J.C.; González, B.; Daquinta, M.; González, J.L.; Desjardins, Y.; Borroto, C.G. Pineapple (Ananas comosus L. Merr) micropropagation in temporary immersion systems. Plant Cell Rep. 1999, 18, 743-748. [CrossRef]

17. Godoy, S.; Tapia, E.; Seit, P.; Andrade, D.; Sanchez, E.; Andrade, P.; Almeida, A.M.; Prieto, H. Temporary immersion systems for the mass propagation of sweet cherry cultivars and cherry rootstocks: Development of a micropropagation procedure and effect of culture conditions on plant quality. In Vitro Cell. Dev. Biol. Plant 2017, 53, 494-504. [CrossRef]

18. An, C.H.; Kim, Y.W.; Moon, H.K.; Yi, J.S. Effects of in vitro culture types on regeneration and acclimatization of yellow poplar (Liriodendron tulipifera L.) from somatic embryos. J. Plant Biotechnol. 2016, 43, 110-118. [CrossRef]

19. Jesionek, A.; Kokotkiewicz, A.; Wlodarska, P.; Zabiegala, B.; Bucinski, A.; Luczkiewicz, M. Bioreactor shoot cultures of Rhododendron tomentosum (Ledum palustre) for a large-scale production of bioactive volatile compounds. Plant Cell Tiss. Organ Cult. 2017, 131, 51-64. [CrossRef]

20. Ramirez-Mosqueda, M.A.; Iglesias-Andreu, L.G. Evaluation of different temporary immersion systems $\left(\right.$ BIT $^{\circledR}$, BIG, and RITA $\left.^{\circledR}\right)$ in the micropropagation of Vanilla planifolia Jacks. In Vitro Cell. Dev. Biol. Plant 2016. [CrossRef]

21. Zhang, Y.Y.; Wu, K.L.; Zhang, J.X.; Deng, R.F.; Duan, J.; Silva, J.A.T.; Huang, W.C.; Zeng, S.J. Embryo development in association with asymbiotic seed germination in vitro of Paphiopedilum armeniacum S.C. Chen et F.Y. Liu. Sci. Rep. 2015, 12, 16356. [CrossRef]

22. Yan, H.; Liang, C.; Li, Y. Improved growth and quality of Siraitia grosvenorii plantlets using a temporary immersion system. Plant Cell Tiss. Organ Cult. 2010, 103, 131-135. [CrossRef]

23. Etienne, H.; Berthouly, M. Temporary immersion systems in plant micropropagation. Plant Cell Tiss. Organ Cult. 2002, 69, 215-231. [CrossRef]

24. Sreedhar, R.V.; Venkatachalam, L.; Neelwarne, B. Hyperhydricity-Related Morphologic and Biochemical Changes in Vanilla (Vanilla planifolia). J. Plant Growth Reg. 2009, 28, 46-57. [CrossRef] 
25. Ramos-Castellá, A.; Iglesias-Andreu, L.G.; Bello-Bello, J.; Lee-Espinosa, H. Improved propagation of vanilla (Vanilla planifolia Jacks. ex Andrews) using a temporary immersion system. In Vitro Cell. Dev. Biol. Plant 2014, 50, 576-581. [CrossRef]

26. Arencibia, A.D.; Vergara, C.; Quiroz, K.; Carrasco, B.; Bravo, C.; Garcia-Gonzales, R. An approach for micropropagation of blueberry (Vaccinium corymbosum L.) plants mediated by temporary immersion bioreactors (TIBs). Am. J. Plant Sci. 2013, 4, 1022-1028. [CrossRef]

27. Berthouly, M.; Etienne, H. Temporary immersion system: A new concept for use liquid medium in mass propagation. In Liquid Culture Systems for In Vitro Plant Propagation; Hvoslef-Eide, A.K., Preil, W., Eds.; Springer (Pays-Bas): Dordrecht, The Netherlands, 2005; pp. 165-195.

28. Zhao, Y.; Sun, W.; Wang, Y.; Saxena, P.K.; Liu, C.Z. Improving mass multiplication of Rhodiola cremulata shoots using temporary immersion bioreactor with forced ventilation. Appl. Biochem. Biotechnol. 2012, 166, 1480-1490. [CrossRef] [PubMed]

29. Aragón, C.E.; Escalona, M.; Rodriguez, R.; Cañal, M.J.; Capote, I.; Pina, D.; González-Olmedo, J. Effect of sucrose, light, and carbon dioxide on plantain micropropagation in temporary immersion bioreactors. In Vitro Cell. Dev. Biol. Plant 2010, 46, 89-94. [CrossRef]

30. Georgiev, V.; Schumann, A.; Pavlov, A.; Bley, T. Temporary immersion systems in plant biotechnology. Eng. Life Sci. 2014, 14, 607-621. [CrossRef]

31. Hazarika, B.N. Acclimatization of tissue-cultured plants. Curr. Sci. 2003, 85, 1704-1712.

32. Dohling, S.; Kumaria, S.; Tandon, P. Multiple shoot induction from axillary bud culture of the medicinal orchid, Dendrobium longicornu. AoB Plants 2012, 2012. [CrossRef]

33. Yang, S.H.; Yeh, D.M. In vitro leaf anatomy, ex vitro photosynthetic behaviors and growth of Calathea orbifolia (Linden) Kennedy plants obtained from semi-solid medium and temporary immersion systems. Plant Cell Tiss. Organ Cult. 2008, 93, 201-207. [CrossRef]

34. Aragón, C.E.; Sánchez, C.; González-Olmedo, J.; Escalona, M.; Carvalho, L. Comparison of plantain plantlets propagated in temporary immersion bioreactors and gelled medium during in vitro growth and acclimatization. Biol. Plant 2014, 58, 29-38. [CrossRef]

35. Decruse, S.W.; Reny, N.; Shyylajakumari, S.; Krishnan, P.N. In vitro propagation and field establishment of Eulophia cullenii (Wight) Bl., a critically endangered orchid of Western Ghats, India through culture of seeds and axenic seedling-derived rhizomes. In Vitro Cell. Dev. Biol. Plant 2013, 49, 520-528. [CrossRef]

36. Kauth, P.J.; Vendrame, W.A.; Kane, M.E. In vitro seed culture and seedlings development of Calopogon tuberosus. Plant Cell Tiss. Organ Cult. 2006, 85, 91-102. [CrossRef] 